\title{
A novel strategy to improve systemic oxygenation in venovenous extracorporeal membrane oxygenation: The " $\chi$-configuration"
}

\author{
Massimo Bonacchi, MD, ${ }^{\mathrm{a}}$ Guy Harmelin, MD, ${ }^{\mathrm{a}}$ Adriano Peris, $\mathrm{MD},{ }^{\mathrm{b}}$ and Guido Sani, $\mathrm{MD}^{\mathrm{a}}$
}

\begin{abstract}
Background: Venovenous extracorporeal membrane oxygenation (VV-ECMO) is used in refractory acute respiratory distress syndrome where lung recovery is the primary goal. For its achievement, adequate extracorporeal blood flow and a maximal separation between oxygenated (inflow) and deoxygenated (outflow) blood flow are essential for reducing the recirculation phenomenon. We introduce the $\chi$-configuration, a new cannulation strategy for VV-ECMO.
\end{abstract}

Patients and Methods: We report our experience with 30 VV-ECMO consecutive patients: in 16 patients (group NS) we applied the $\chi$-configuration, which consists of a particular right atrial cannula arrangement and a selfmade modified inflow cannula, consisting of an outflow multihole venous cannula that was inserted percutaneously through the right femoral vein, into the right atrium, just below on the superior vena cava, and a self-made modified curved inflow cannula (inserted percutaneously through the right internal jugular vein) that, in its terminal segment, permitted the tip to be positioned close to the tricuspid valve. In 14 patients (group C) we applied the standard femoro-jugular VV-ECMO 2-cannula setting. In both groups, efficacy of blood oxygenation was obtained by gas-blood analysis, by blood samples obtained at arterial, central venous, and pulmonary artery lines, and by ECMO inflow and outflow lines. The recirculation fraction was obtained by a specific bedside formula.

Results: No differences were noted between groups regarding the pre-ECMO patient characteristics. No com-
plications during cannulation were recorded. In group NS, on-ECMO time, post-ECMO mechanical ventilation
time, and ECMO overall results were significantly better than in group C. During high-flow VV-ECMO, pulmo-
nary and systemic arterial oxygen saturation and arterial oxygen tension were significantly higher in group NS,
and blood recirculation fraction was significantly lower.

Conclusions: Our data indicate that $\chi$-configuration can be safe, feasible, and more effective than conventional VV-ECMO. It permits near complete drainage of the desaturated blood and a preferential oxygenated blood inflow toward the tricuspid valve, resulting in a significant reduction of recirculation, thereby improving the patient's oxygenation. Our innovative strategy reduces on-ECMO and post-ECMO mechanical ventilation time, gives a faster and better pulmonary recovery, improves survival, and can reduce hospital costs. (J Thorac Cardiovasc Surg 2011;142:1197-204)

Video clip is available online.

Severe acute respiratory failure (SARF) is characterized by a profound deterioration in oxygenation and/or ventilation despite maximal supportive respiratory therapy. ${ }^{1}$ Although SARF is relatively infrequent in adults, ${ }^{2}$ it often results in

From Cardiac Surgery, ${ }^{\mathrm{a}}$ Medical and Surgical Critical Care Department, University of Florence, Firenze, Italy; and Anesthesia and Intensive Care Unit, ${ }^{\mathrm{b}}$ Emergency Department, Careggi Teacing Hospital, Florence, Italy.

Disclosures: Authors have nothing to disclose with regard to commercial support.

Received for publication Oct 4, 2010; revisions received Dec 26, 2010; accepted for publication Jan 24, 2011; available ahead of print March 14, 2011.

Address for reprints: Massimo Bonacchi, MD, Cardiac Surgery, Medical and Surgical Critical Care Department, Careggi Teaching Hospital, Viale Morgagni 85, 50134,

Florence, Italy (E-mail: mbonacchi@unifi.it).

$0022-5223 / \$ 36.00$

Copyright (C) 2011 by The American Association for Thoracic Surgery

doi:10.1016/j.jtcvs.2011.01.046 devastating consequences. In the past few years, attempts have been made to optimize lung-protective ventilation. ${ }^{3-5}$ Ventilator lung injury (VILI) is an important limiting factor of lung recovery ${ }^{2,6}$; therefore, some patients with refractory SARF require unconventional mechanical ventilation to prevent additional lung injury, life-threatening hypoxemia, and death.

Extracorporeal membrane oxygenation (ECMO) was first introduced clinically in $1972 .^{7}$ Significant controversy surrounds the use of ECMO in the nonneonatal population. ${ }^{8-10}$ The Conventional Ventilation or ECMO for Severe Adult Respiratory Failure (CESAR) study ${ }^{11}$ demonstrated an improved outcome with ECMO support in adult patients with seemingly irreversible SARF. In the clinical setting, venovenous ECMO (VV-ECMO) allows "pulmonary rest" and recovery but is limited by the "recirculation phenomenon." $" 8-10$

Since 2007 we have been developing an extracorporeal life support program. In isolated patients with adult 


$$
\begin{aligned}
& \text { Abbreviations and Acronyms } \\
& \begin{array}{ll}
\mathrm{BRF}= & \text { blood recirculation fraction } \\
\mathrm{CESAR}= & \text { Conventional ventilation or ECMO for } \\
& \text { Severe Adult Respiratory failure } \\
\mathrm{CO}= & \text { cardiac output } \\
\mathrm{ECMO}= & \text { extracorporeal membrane oxygenation } \\
\mathrm{FIO}_{2}= & \text { inspired oxygen fraction } \\
\mathrm{PaCO}_{2}= & \text { arterial carbon dioxide tension } \\
\mathrm{SVC}= & \text { superior vena cava } \\
\mathrm{SARF} & =\text { severe acute respiratory failure } \\
\mathrm{VILI}= & \text { ventilator lung injury } \\
\mathrm{VV}- & =\text { venovenous extracorporeal membrane } \\
\mathrm{ECMO} & \text { oxygenation }
\end{array}
\end{aligned}
$$

respiratory distress syndrome, we used the VV-ECMO with a high flow strategy by setting the ventilator to the most protective modality and allowing lung rest, ${ }^{11}$ reducing VILI, and thus a producing a faster lung recovery. ${ }^{4,5}$ In cases in which there was limited blood drainage and, consequently, limited VV-ECMO flow in respect to patient cardiac output (CO), we found inadequate blood separation between the venous blood drainage and the inflow arterialized blood returned by ECMO augmenting the amount of the blood recirculation fraction (BRF).

On the basis of its intrinsic setting, BRF between outflow and inflow cannulas remains a clinical obstacle, whereas VV-ECMO high blood flow per se impairs systemic oxygenation and contradicts the primary purpose of this practice. The efficacy of VV-ECMO support can be limited even when higher flow speeds are used. Various cannula settings have been proposed to resolve this problem. ${ }^{12,13}$ To date, none has proven sufficient clinical data in terms of radically resolving these problems.

In August 2007, we developed a novel strategy, the " $\chi$-configuration," to obtain an optimal extracorporeal blood oxygenation.

The aim of this study was to evaluate the feasibility, safety, efficacy, and efficiency of the $\chi$-configuration in comparison with the classic 2-cannula VV-ECMO.

\section{PATIENTS AND METHODS \\ Patient Characteristics}

From August 2007 to October 2010, 30 patients with isolated (adequate cardiac performance) refractory SARF were treated with VV-ECMO. All patients had unsuccessful maximal conventional ventilator and medical therapy. The protocol was approved by the central institutional review board. All patients or their relatives signed informed consent forms.

We applied the Extracorporeal Life Support Organization indications and contraindication to VV-ECMO [http://www.elso.med.umich.edu/ Guidelines.html].

As previously reported, ${ }^{14}$ our ECMO team caring for these patients believed that the patients would not survive without ECMO. All of our patients had a partial pressure of oxygen less than $60 \mathrm{~mm} \mathrm{Hg}$ and an oxygenation index of almost 40 . Additionally, all members of the team believed that the patients had a reasonable chance of survival if the respiratory illness could be supported. Exclusion criteria included an irreversible underlying pulmonary injury, mechanical ventilation at high settings (inspired oxygen fraction $\left[\mathrm{FIO}_{2}\right]>0.9$, end inspiratory plateau pressure $>$ $30 \mathrm{~cm} \mathrm{H}_{2} \mathrm{O}$ ) for 7 days or more, ongoing bleeding, central nervous system hemorrhage, or the coexistence of any condition that would prevent systemic anticoagulation.

Patients were divided randomly into 2 groups: group NS ( $\mathrm{n}=16$ patients) underwent the $\chi$-configuration and group $\mathrm{C}(\mathrm{n}=14$ patients $)$ underwent a standard 2-cannula femoro-jugular VV-ECMO. ${ }^{15}$ Patients' demographics and clinical characteristics are elaborated in Table 1.

\section{Cannulation Strategy and VV-ECMO Setting}

All VV-ECMO procedures were performed at the bedside. In all patients we used arterial and venous bio-coated cannulas. Both inflow and outflow cannulas were inserted by the Seldinger techniques and cannula position was assisted with transesophageal echography guidiance. The sizes of cannulas were related to patient anatomic features. $\mathrm{CO}$ and mixed venous oxygen saturation were continuously recorded. The oxygenator $\mathrm{FiO}_{2}$ was set to $100 \%$ and gas flow was set to $1: 1$ with blood flow. Later on it was titrated to the patient's arterial carbon dioxide tension $\left(\mathrm{PaCO}_{2}\right)$.

In group C (14 patients), we applied a standard 2-cannula venovenous technique. In brief, deoxygenated blood was drained from the right atrium through a cannula inserted percutaneously into the right femoral vein. The oxygenated blood was returned via a short cannula inserted in the right internal jugular vein just distal to the superior vena cava (SVC).

In goup NS (16 patients), we applied a novel cannulation setting, the $\chi$-configuration: this is an original 2-cannula VV-ECMO cannulation strategy, allowing a high-flow ECMO and reducing BRF by inducing a preferential oxygenated blood flow directly through the tricuspid valve.

In detail, to permit a high-flow VV-ECMO for near complete extracorporeal blood oxygenation, an outflow multihole venous cannula was inserted percutaneously through the right femoral vein into the right atrium, just below the SVC: this position maximizes desaturated blood draining, intercepting near total blood returned from both venae cavae.

For the oxygenated blood reinfusion, we used a self-made and modified long arterial inflow cannula $(23 \mathrm{~cm})$. After removal of the mandrel, it acquired a $60^{\circ}$ angle in its terminal segment, and after atrial insertion via the right internal jugular vein, the tip could be positioned close to the tricuspid valve. This cannula configuration allowed preferential oxygenated blood flow through the tricuspid valve to the right ventricle and, as a result, to the pulmonary and systemic circulations, reducing dramatically the VV-ECMO recirculation phenomenon.

The inflow cannula was modified by making a $60^{\circ}$ curvature in its distal third by a three-five $3-0$ polypropylene, $0.5 / 1 \mathrm{~cm}$ large, single stitch that was knotted over the tip and terminated after 3 to $4 \mathrm{~cm}$ with a soft left rotation (Figure 1). Selection of a monofilament stitch was favorable as it is less prone to infection and coagulation activation. The tip orientation was correlated to the female Luer-Lok of the cannula. After a cannula linear restoration with remandrination, it was inserted in the right internal jugular vein and delivered to the right atrium with the tip near the tricuspid valve (Figure 2). Correct cannula position was verified with transesophageal echocardiography. Chest radiography showed the curvature of the radiopaque inflow cannula (Figure 3).

\section{Ventilation Strategy, Pulmonary Care, Patient Monitoring, and BRF Calculation}

Our ventilation strategy during ECMO was as follows: once maximal ECMO flow was achieved, ventilation was gradually reduced. The target for optimal patient oxygenation was considered to be an arterial oxygen saturation $\left(\mathrm{SaO}_{2}\right)$ of $95 \%$ or more. Protective ventilator settings were as follows: pressure control, peak inspiratory pressure less than $30 \mathrm{~cm} \mathrm{H}_{2} \mathrm{O}$ (better if $<25 \mathrm{~mm} \mathrm{Hg}$ ), and positive end-expiratory pressure between 10 and $15 \mathrm{~cm}$ 
TABLE 1. Pre-ECMO group NS and group C data. No statistical differences are found in patient characteristics, SARF etiology, pulmonary functional status, or laboratory and arterial blood gas analysis

\begin{tabular}{|c|c|c|c|}
\hline Variable & Group NS & Group C & $\begin{array}{c}P \\
\text { values }\end{array}$ \\
\hline Patients (N) & 16 & 14 & \\
\hline Male $(\mathrm{N})$ & $13(81.25)$ & (78.57) & .818 \\
\hline Age (y) & $42.3 \pm 21.5$ & $43.8 \pm 24.7$ & .862 \\
\hline $\operatorname{BSA}\left(\mathrm{m}^{2}\right)$ & $1.92 \pm 0.21$ & $1.85 \pm 0.24$ & .838 \\
\hline Renal substitution therapy & $2(12.5)$ & $2(14.3)$ & .683 \\
\hline \multicolumn{4}{|l|}{ SARF etiology } \\
\hline Bacterial pneumonia & $8(50)$ & $8(57)$ & .695 \\
\hline Viral pneumonia & $4(25)$ & $3(21.5)$ & .839 \\
\hline Trauma/postoperation & $2(12.5)$ & $2(4.3)$ & .693 \\
\hline Other & $2(12.5)$ & $1(7.15)$ & .902 \\
\hline \multicolumn{4}{|l|}{ Mechanical ventilatory setting } \\
\hline Ventilation support (d) & $6.78 \pm 1.8$ & $6.45 \pm 2.2$ & .655 \\
\hline $\mathrm{FIO}_{2}$ & $0.99 \pm 0.07$ & $0.98 \pm 0.08$ & .717 \\
\hline PIP $\left(\mathrm{cm} \mathrm{H}_{2} \mathrm{O}\right)$ & $44.3 \pm 7.3$ & $41.8 \pm 9.5$ & .422 \\
\hline $\operatorname{PEEP}\left(\mathrm{cm} \mathrm{H}_{2} \mathrm{O}\right)$ & $13.2 \pm 3.5$ & $12.4 \pm 2.7$ & .494 \\
\hline $\begin{array}{l}\text { Pulmonary compliance } \\
\left(\mathrm{mL} / \mathrm{cm}^{2}\right)\end{array}$ & $11.3 \pm 5.4$ & $12.5 \pm 6.1$ & .573 \\
\hline Oxygenation index & $63.2 \pm 11.8$ & $59.1 \pm 10.5$ & .326 \\
\hline Murray score & $3.42 \pm 0.45$ & $3.29 \pm 0.53$ & .473 \\
\hline \multicolumn{4}{|l|}{ Laboratory values } \\
\hline WBC count $\left(\mathrm{N}^{*} 1000 / \mathrm{ml}\right)$ & $23.5 \pm 9.3$ & $22.8 \pm 6.9$ & .819 \\
\hline $\operatorname{Hgb}(\mathrm{g} / \mathrm{dL})$ & $12.2 \pm 3.6$ & $12.5 \pm 4.1$ & .832 \\
\hline Platelet count $(\mathrm{N} \cdot 1000 / \mathrm{mL})$ & $201.8 \pm 43.7$ & $220.5 \pm 54.8$ & .307 \\
\hline Serum creatinine $(\mathrm{mg} / \mathrm{dL})$ & $0.985 \pm 0.12$ & $0.96 \pm 0.23$ & .707 \\
\hline \multicolumn{4}{|l|}{ Arterial blood gas values } \\
\hline $\mathrm{pH}$ & $7.25 \pm 0.03$ & $7.27 \pm 0.05$ & .188 \\
\hline $\mathrm{PaO}_{2}(\mathrm{~mm} \mathrm{Hg})$ & $57.8 \pm 2.1$ & $58.7 \pm 2.3$ & .272 \\
\hline $\mathrm{PaCO}_{2}(\mathrm{~mm} \mathrm{Hg})$ & $80.8 \pm 10.4$ & $76.2 \pm 12.8$ & .287 \\
\hline $\mathrm{SaO}_{2}(\%)$ & $76.3 \pm 5.2$ & $78.4 \pm 6.5$ & .334 \\
\hline $\mathrm{PaO}_{2} / \mathrm{FIO}_{2}$ ratio & $0.578 \pm 0.021$ & $0.587 \pm 0.023$ & .272 \\
\hline Time on ECMO (h) & $227.9 \pm 92.7$ & $314.7 \pm 102.7$ & .022 \\
\hline VV-ECMO successful & $16(100)$ & $9(64.2)$ & .044 \\
\hline $\begin{array}{l}\text { Post-ECMO mechanical } \\
\text { ventilation (d) }\end{array}$ & $2.8 \pm 1.6$ & $4.7 \pm 3.2$ & .048 \\
\hline ICU discharge survival & $14(87.5)$ & $8(57.14)$ & .058 \\
\hline Hospital discharge survival & $14(87.5)$ & $8(57.14)$ & .058 \\
\hline \multicolumn{4}{|l|}{ Cause of death } \\
\hline Sepsis & 1 & 1 & \\
\hline MOF & & 4 & \\
\hline Cerebral death & 1 & 1 & \\
\hline
\end{tabular}

Figures in parentheses represent percentage values. Values are mean \pm standard deviation. $P<.05$ is the significant difference. ECMO, Extracorporeal membrane oxygenation; SARF, severe acute respiratory failure; $B S A$, body surface area; $\mathrm{FIO}_{2}$, fraction of inspired oxygen; PIP, peak inspiratory pressure; PEEP, positive endexpiratory pressure; $\mathrm{WBC}$, white blood cells; $\mathrm{Hg}$, hemoglobin concentration; $\mathrm{PaO}_{2}$, arterial oxygen tension; $\mathrm{PaCO}_{2}$, arterial carbon dioxide tension; $\mathrm{SaO}_{2}$, arterial oxygen saturation; $V V$, venovenous; $I C U$, intensive care unit; $M O F$, multiorgan failure.

$\mathrm{H}_{2} \mathrm{O}$, depending on pressure/volume curves. Controlled respiratory frequency was reduced to 4 to 10 breaths $/ \mathrm{min}$. $\mathrm{FIO}_{2}$ was reduced to 0.5 or lower, whenever possible. ${ }^{2}$ ECMO flow was adjusted to keep arterial saturation at $95 \%$ or more with normal carbon dioxide levels. Patients were treated as soon as possible with continuous positive airway pressure or spontaneous breathing. Lungs were evaluated periodically by computed tomographic scan, chest X-ray, and daily lung ultrasound examinations. ${ }^{14}$ Blood was transfused when required to reach hemoglobin levels of 11 to $13 \mathrm{mg} / \mathrm{dL}$. If sufficient lung rest settings were still not achieved within 2 to 3 days, standard perfusion was converted to modified perfusion: in 2 group $\mathrm{C}$ patients venoarterial ECMO configuration was applied.

A Swan-Ganz catheter (Edwards LifeSciences, Irvine, Calif) was inserted to measure $\mathrm{CO}$, pulmonary vascular resistance, pulmonary blood gas analysis, and continuous oxygen saturation in the pulmonary artery. Functional oxygen saturation was monitored continuously as well. Central venous blood gas analysis was obtained from a central venous catheter (tip positioned in the distal portion of the SVC). Circuit monitors included preoxygenator and postoxygenator blood gas analysis and pressure.

As for ECMO weaning and trial off, once pulmonary function improved, verified by increased pulmonary compliance and improved chest radiograph and computed tomography, the extracorporeal blood flow was reduced (using steps of $10 \%$ of maximal flow each 6-8 hours). During this ECMO reduction, monitoring central venous and arterial oxygen saturation was essential. When the ECMO flow was reduced to such a low level that it no longer contributed substantially to the gas exchange $\left(1.5 \mathrm{~L} \cdot \mathrm{m}^{-2}\right.$. $\min ^{-1}$ ), a trial off was indicated. If lung function was adequate at the acceptable ventilator settings for an hour or more, the patient was ready for decannulation.

$\mathrm{BRF}$ is defined as the portion of blood that has just been oxygenated within the ECMO circuit oxygenator and will flow directly from the reinfusion site and be taken by the venous drainage cannula, instead of being delivered to the patient's circulation. Several complex and invasive methods were introduced for RBF calculation. ${ }^{12,13,15}$ For BRF evaluation, we applied a simple bedside formula, using evaluation of blood oxygen saturation obtained from different sites according to the formula:

$$
\mathrm{BRF}(\%)=\left(\text { SpreOxy }-\mathrm{Scvo}_{2} / \mathrm{SpostOxy}-\mathrm{Scvo}_{2}\right) \times 100
$$

where SpreOxy is the oxygen saturation level of the blood entering the oxygenator, SpostOxy is the oxygen saturation level of the blood exiting the oxygenator, and $\mathrm{ScvO}_{2}$ is cerebral oxygen saturation. For cerebral oxygen saturation, ideally we would need to use the mixed venous oxygen saturation, but is impossible to measure the true mixed venous oxygen saturation during VV-ECMO. It was obtained by sampling blood from the SVC proximal portion.

\section{ECMO Equipment and Anticoagulation Strategy}

The ECMO equipment used (pump, oxygenator, and cannulas) were all bio-coated.

Heparin infusion, applied directly within the ECMO circuit, with a preoxygenator stopcock, was monitored and titrated every 2 hours by a bedside measurement of activated partial thromboplastin time. Anticoagulation was maintained at a mean (standard deviation) of 55.9 (7.6) seconds for all patients. In case of renal replacement therapy during the ECMO procedure, a continuous venovenous hemodiafiltration circuit was assembled directly into the ECMO circuit (aspiration and restitution on prepump line).

\section{Evaluation of $\chi$-Configuration Efficiency and Efficacy}

All group NS and group C patients were evaluated to determine the efficiency and efficacy of different types of VV-ECMO in the systemic oxygenation.

Under the same ECMO flow (equal to $80 \% \mathrm{CO}$ ) and protective mechanical ventilation as previously reported, blood samples were drawn from the patient's radial artery, pulmonary artery, and central venous preoxygenator and postoxygenator lines. All measurements were repeated 3 times. Any individual measurement at each site that differed from the other 2 measurements by more than $10 \%$ was discarded and another measurement was made. The results were averaged for subsequent analysis. For all patients, BRF was calculated as well. All data are reported in Table 1. 

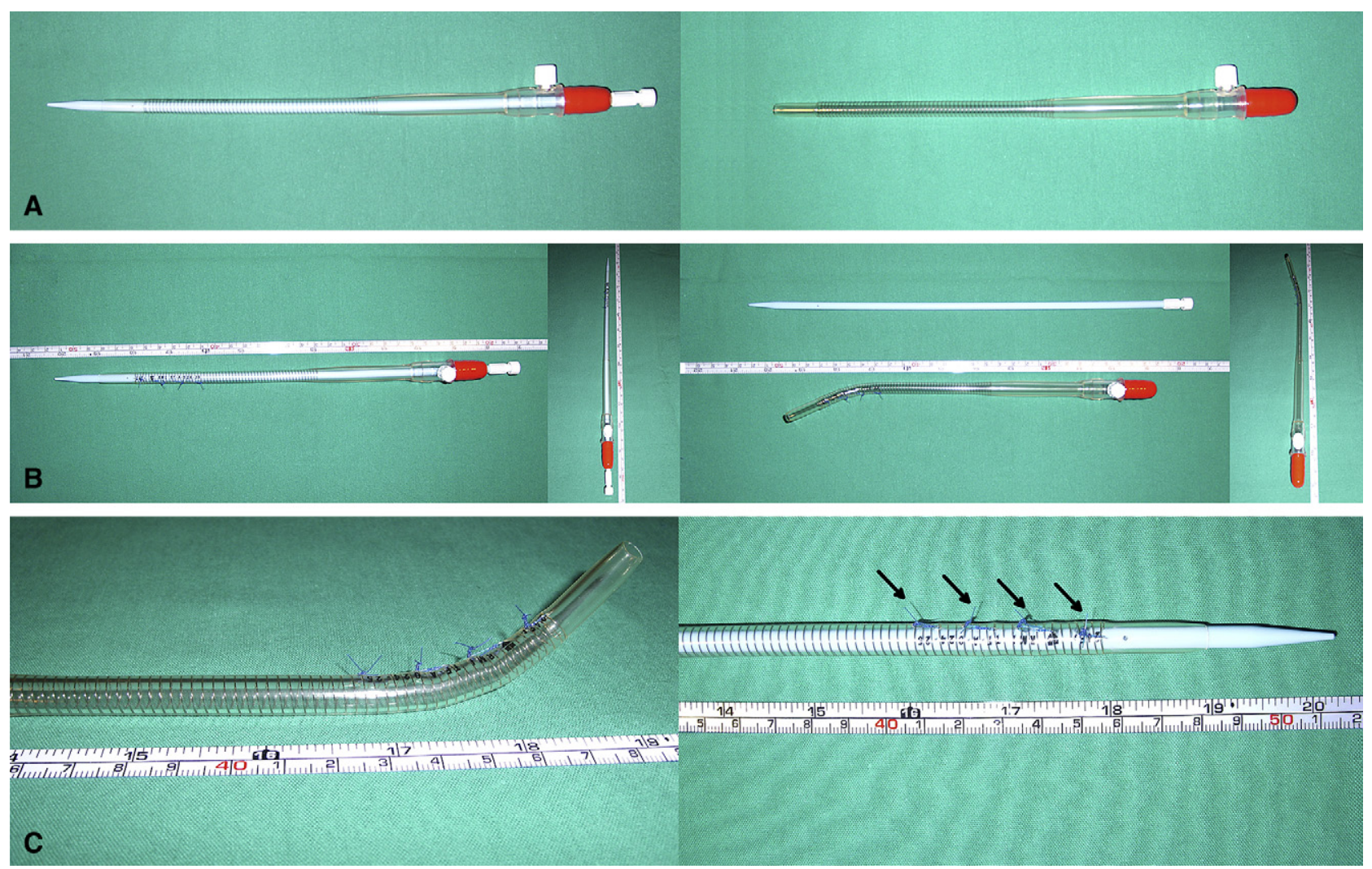

FIGURE 1. The "customized" arterial cannula. A, The nonmodified cannula: with the mandrel in place (left) and with the mandrel removed (right). B, The self-made modified arterial cannula: with the mandrel in place (left) and with the mandrel removed (right). C, The customized cannula tip (particular): with the mandrel in place (left) and with the mandrel removed (right). The arrows indicate the polypropylene single stitches making a $60^{\circ}$ curvature with a soft left rotation.

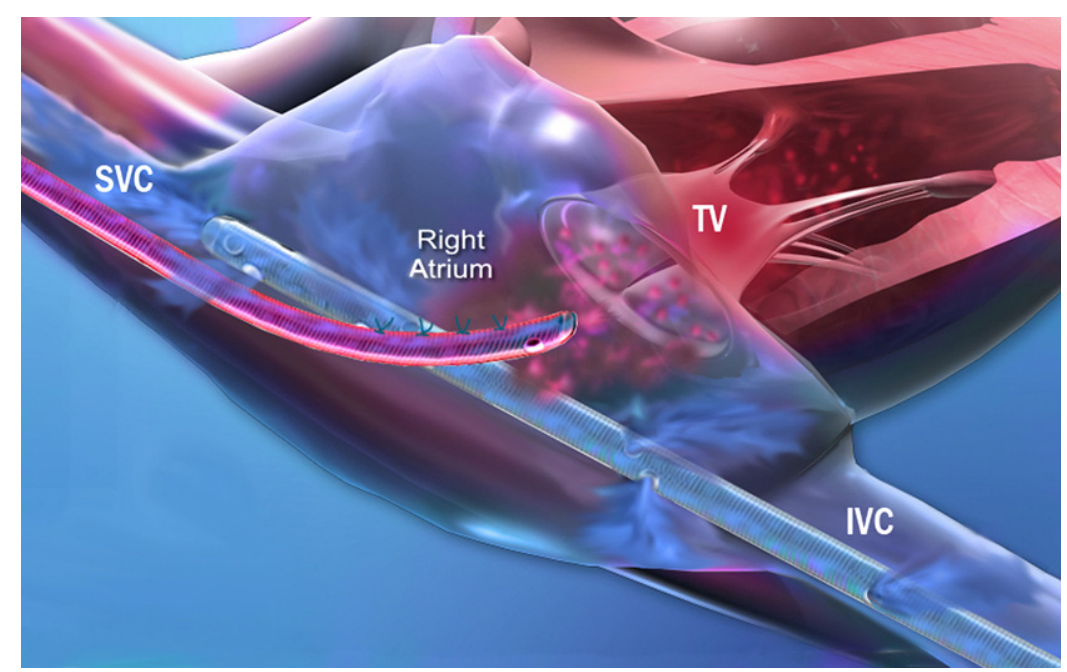

FIGURE 2. The $\chi$-configuration modified VV-ECMO cannulation. Blood is drained from the two venae cavae (superior [SVC] and inferior [IVC]) by a multihole cannula placed, through the right femoral vein, to the right atrium with the tip just below on the SVC. Arterialized blood is returned to the right atrium through the self-made modified arterial cannula $(23 \mathrm{~cm}$ long) placed through the right internal jugular vein with the tip toward the tricuspid valve (TV). A polypropylene stitch was used to make 4 consecutive bites over the distal $3-4 \mathrm{~cm}$ of the arterial cannula to create the desired curvature and a soft left rotation. 


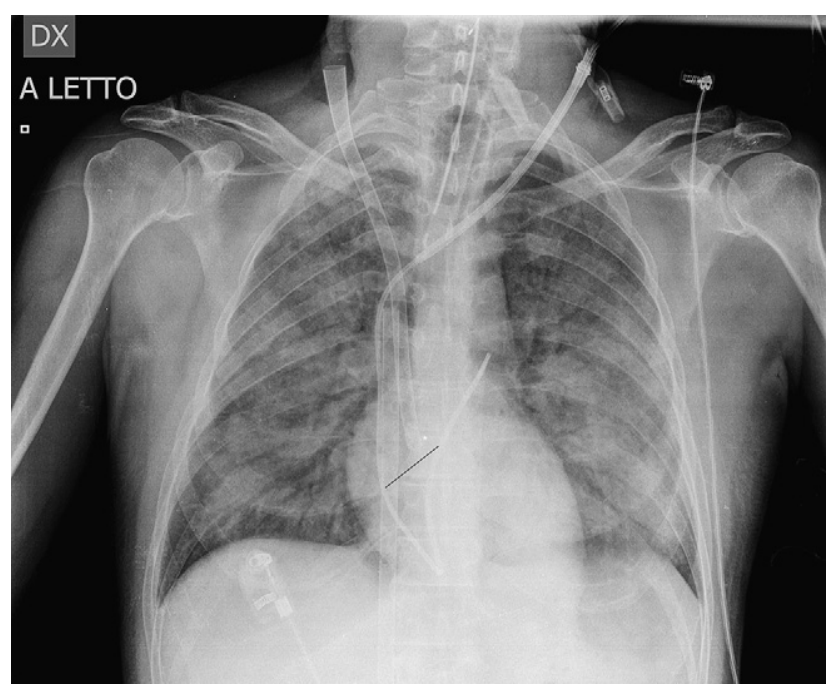

FIGURE 3. Plain chest $x$-ray film shows the lazy curvature of the in flow cannula from the right neck base toward the right ventricle. The cannula tip (*) and the tricuspid valve plan (continuous line) are marked. The drawing cannula is located in right atrium below the superior vena cava.

\section{Statistical Analysis}

Wilcoxon tests were used to compare continuous variables between the 2 groups, whereas Pearson $\chi^{2}$ tests were used for categorical variables. All data collection and statistical analysis was performed using SPSS version 18 software (SPSS Inc, Chicago, Ill). Results are presented as mean values \pm standard deviation unless otherwise noted.

\section{RESULTS}

As reported in Table 1, there were no significant differences between the 2 groups in terms of demographic data, SARF etiology, associated pathologic conditions, body mass index, and hemocoagulative and blood gas analysis data. No differences were found between groups in immediate pre-ECMO evaluation, duration of mechanical ventilation support $(6.78 \pm 1.8$ days vs $6.45 \pm 2.2$ days; $P=.45)$, and pulmonary functional status: pulmonary compliance, oxygen index, Murray score, and ventilator setting were similar between groups $(P>.05$ for all data). Laboratory values and arterial blood gas values were similar as well. No complications were reported during insertion of VV-ECMO cannula in group NS or in group C patients.

Minor bleeding, owing to heparin infusion, was the only complication during ECMO time: 3 patients in group $\mathrm{C}$ and 2 in group NS $(P>.05)$ needed blood transfusion for prolonged oropharyngeal or cannulation site bleeding.

As reported in Table 1, ECMO time was significantly longer in group $\mathrm{C}$ than in group NS (227.9 \pm 92.7 hours vs $314.7 \pm 102.7$ hours; $P<.0215$ ). Successful VV-ECMO is intended as the oxygenation target of at least "systemic arterial oxygen saturation" $\geq 95 \%$, reached with sufficient protective pulmonary ventilation, the possibility to wean ECMO with pulmonary function recovery, and survival of more that 48 hours without SARF relapse. This result was obtained in all NS group patients and in only $9(64.2 \%) \mathrm{C}$ group patients $(P=.044)$. In fact, in 1 group $C$ patient, ECMO was converted (after 18 hours) to venoarterial configuration to obtain a sufficient systemic blood oxygenation, and in 4 other patients no sufficient pulmonary recovery was obtained. After ECMO discontinuation, the time of mechanical ventilation required was significantly shorter in group NS ( $2.8 \pm 1.6$ days vs $4.7 \pm 3.2$ days; $P=.048)$.

The intensive care unit discharge and hospital discharge survivals were better in group NS $(87.5 \%$ vs $57.14 \%$; $P=.058$, respectively), although the difference did not reach a statistical significance. The cause of death is shown in Table 1 for all nonsurvivors. In 4 group $\mathrm{C}$ patients the cause of death was irreversible pulmonary fibrosis and multiple organ dysfunction, in 1 other (a 64-year-old woman) subarachnoid hemorrhage, and in a 54-year-old man systemic secondary infection owing to Aspergillus appeared 7 days after ECMO discontinuation.

In group NS, causes of death were cerebral death secondary to severe traumatic brain injury in a 19-year-old man and a multiresistant Pseudomonas-related sepsis in a 48-yearold man. In these 2 patients, after brain death was confirmed multiple organ donations were accomplished.

Assessment of VV-ECMO started after patient parameters stabilized (mean time $=7.48 \pm 5.8$ hours and $9.59 \pm$ 6.2 hours in groups NS and $\mathrm{C}$, respectively; $P=.345$ ). At VV-ECMO flow equal to $80 \%$ of the patient's CO, the $\chi$-configuration seemed to guarantee a better oxygenation and a reduction of BRF. The detailed results are shown in Table 2.

During high-flow VV-ECMO, pulmonary, systemic arterial oxygen saturation, and arterial oxygen tension were significantly higher in group NS patients $(97.6 \pm 1.2$ vs $91.2 \pm$ $3.2 ; P<.001 ; 98.5 \pm 1.5$ vs $95.7 \pm 1.67 ; P=.0063$; and $97.8 \pm 12.8$ vs $85.3 \pm 19.5 ; P=.044$; respectively). To reach a systemic arterial oxygen saturation of $95 \%$ or more, the group $\mathrm{C}$ ventilator setting was necessarily less protective. Significant differences between groups were noted in terms of $\mathrm{FIO}_{2}$, minute volume, tidal volume, and intrapericardial pressure setting $(25.7 \pm 9.7$ vs $37.9 \pm 11.6$; $P<.0001 ; 765.6 \pm 154.3$ vs $1858.8 \pm 534.65 ; P<.0001 ;$ $95.7 \pm 56.8$ vs $154.9 \pm 98.7 ; P=.0395 ;$ and $22.3 \pm 4.6$ vs $28.7 \pm 5.1 ; P=.0012$, respectively). In group C, the pulmonary residual function employment and contribution are essential to obtain the desired level of oxygenation: the improvement in oxygen saturation and partial pressure in the radial artery versus the pulmonary artery is significant $(95.7 \pm 1.67$ vs $91.2 \pm 3.2[P=.0001]$ and $85.3 \pm 19.5$ vs $83.8 \pm 14.7[P=.0487]$, respectively), while not in group NS $(98.5 \pm 1.5$ vs $97.6 \pm 1.2[P=.071]$ and $97.8 \pm 12.8$ vs $97.3 \pm 10.3[P=.904]$, respectively). The difference in oxygen content in the pulmonary artery was significantly higher in the $\chi$-configuration than in the conventional configuration $(17.56 \pm 1.23$ vs $16.09 \pm 1.45$ 
TABLE 2. Evaluation of efficacy and efficiency of patient oxygenation, oxygen delivery, and reduction of BRF of VV-ECMO using $\chi$-configuration versus conventional 2-cannula configuration. Reported oxygenation data are obtained at the same ECMO flow (equal to $80 \%$ of patient's $\mathrm{CO}$ ) and ventilator setting to achieve an $\mathrm{So}_{2} \geq \mathbf{9 5} \%$ in radial artery

\begin{tabular}{|c|c|c|c|}
\hline Parameters & Group NS & Group C & $\begin{array}{c}P \\
\text { value }\end{array}$ \\
\hline \multicolumn{4}{|l|}{ Ventilator setting } \\
\hline $\mathrm{FIO}_{2}$ & $25.7 \pm 9.7$ & $37.9 \pm 11.6$ & .004 \\
\hline $\mathrm{MV}(\mathrm{mL})$ & $765.6 \pm 154.3$ & $1813.9 \pm 534.6$ & $<.0001$ \\
\hline $\mathrm{TV}(\mathrm{mL})$ & $95.7 \pm 56.8$ & $164.9 \pm 98.7$ & .024 \\
\hline Breaths/min & $8 \pm 3.8$ & $11 \pm 5.2$ & .079 \\
\hline $\operatorname{PEEP}\left(\mathrm{cm} \mathrm{H}_{2} \mathrm{O}\right)$ & $10.4 \pm 2.6$ & $12.3 \pm 4.3$ & .1484 \\
\hline $\mathrm{PIP}\left(\mathrm{cm} \mathrm{H}_{2} \mathrm{O}\right)$ & $22.3 \pm 4.6$ & $28.7 \pm 5.1$ & .0011 \\
\hline \multicolumn{4}{|l|}{ Hemodynamic } \\
\hline $\mathrm{CO}(\mathrm{L} / \mathrm{min})$ & $8.2 \pm 1.7$ & $7.4 \pm 1.53$ & .19 \\
\hline $\operatorname{BSA}\left(\mathrm{m}^{2}\right)$ & $1.92 \pm 0.21$ & $1.85 \pm 0.24$ & .401 \\
\hline $\begin{array}{l}\mathrm{CI}(\mathrm{CO} / \mathrm{BSA} \mathrm{L} \\
\left.\quad \cdot \mathrm{min}^{-1} \cdot \mathrm{m}^{-2}\right)\end{array}$ & $4.27 \pm 0.93$ & $4 \pm 0.85$ & .415 \\
\hline \multicolumn{4}{|l|}{ VV-ECMO setting } \\
\hline \multicolumn{4}{|l|}{ ECMO flow $(\mathrm{L} / \mathrm{min})$} \\
\hline $\begin{array}{l}\text { Equal to } 80 \% \\
\text { of } \mathrm{CO}\end{array}$ & $6.56 \pm 0.9$ & $5.92 \pm 1.12$ & .094 \\
\hline $\begin{array}{l}\text { ECMO gas flow } \\
\text { (L/min) }\end{array}$ & $7.2 \pm 1.3$ & $6.5 \pm 1.8$ & .228 \\
\hline ECMO $\mathrm{FIO}_{2}$ & $100 \%$ & $100 \%$ & \\
\hline \multicolumn{4}{|c|}{ Blood gas analysis values } \\
\hline \multicolumn{4}{|c|}{ Radial artery blood samples } \\
\hline $\mathrm{pH}$ & $7.442 \pm 1.3$ & $7.45 \pm 1.7$ & .988 \\
\hline $\mathrm{PCO}_{2}(\mathrm{~mm} \mathrm{Hg})$ & $35.6 \pm 2.8$ & $33.4 \pm 4.6$ & .119 \\
\hline $\mathrm{Po}_{2}(\mathrm{~mm} \mathrm{Hg})$ & $97.8 \pm 12.8$ & $85.3 \pm 19.5$ & .044 \\
\hline $\mathrm{Hgb}(\mathrm{g} / \mathrm{dL})$ & $12.4 \pm 3.5$ & $12.7 \pm 4.6$ & .84 \\
\hline $\mathrm{SO}_{2}(\%)$ & $98.5 \pm 1.5$ & $95.7 \pm 1.67$ & .0063 \\
\hline \multicolumn{4}{|c|}{ Pulmonary artery blood samples } \\
\hline $\mathrm{pH}$ & $7.439 \pm 0.12$ & $7.425 \pm 0.196$ & .813 \\
\hline $\mathrm{PCO}_{2}(\mathrm{~mm} \mathrm{Hg})$ & $36.1 \pm 4.3$ & $39.8 \pm 6.2$ & .065 \\
\hline $\mathrm{Po}_{2}(\mathrm{~mm} \mathrm{Hg})$ & $97.3 \pm 10.3$ & $83.8 \pm 14.7$ & .0065 \\
\hline $\operatorname{Hgb}(\mathrm{g} / \mathrm{dL})$ & $12.5 \pm 2.7$ & $12.3 \pm 3.6$ & .8635 \\
\hline $\mathrm{SO}_{2}(\%)$ & $97.6 \pm 1.2$ & $91.2 \pm 3.2$ & $<.001$ \\
\hline \multicolumn{4}{|c|}{ Central venous samples } \\
\hline $\mathrm{pH}$ & $7.31 \pm 0.87$ & $7.28 \pm 1.1$ & .934 \\
\hline $\mathrm{PCO}_{2}(\mathrm{~mm} \mathrm{Hg})$ & $50.9 \pm 2.5$ & $51.2 \pm 3.2$ & .775 \\
\hline $\mathrm{Po}_{2}(\mathrm{~mm} \mathrm{Hg})$ & $43.1 \pm 3.8$ & $40.2 \pm 5.3$ & .093 \\
\hline $\mathrm{Hgb}(\mathrm{g} / \mathrm{dL})$ & $12.3 \pm 2.9$ & $11.7 \pm 3.8$ & .628 \\
\hline $\mathrm{ScvO}_{2}(\%)$ & $77.4 \pm 4.7$ & $75.2 \pm 9.2$ & .408 \\
\hline \multicolumn{4}{|c|}{ Preoxygenator samples } \\
\hline $\mathrm{pH}$ & $7.36 \pm 0.93$ & $7.37 \pm 1.43$ & .982 \\
\hline $\mathrm{PCO}_{2}(\mathrm{~mm} \mathrm{Hg})$ & $49.8 \pm 2.8$ & $46.3 \pm 4.8$ & .019 \\
\hline $\mathrm{Po}_{2}(\mathrm{~mm} \mathrm{Hg})$ & $42.7 \pm 4.2$ & $48.6 \pm 5.7$ & .003 \\
\hline $\operatorname{Hgb}(\mathrm{g} / \mathrm{dL})$ & $12.1 \pm 3.1$ & $12.4 \pm 3.5$ & .805 \\
\hline $\mathrm{SO}_{2}(\%)$ & $78.6 \pm 2.1$ & $82.5 \pm 7.2$ & .047 \\
\hline \multicolumn{4}{|c|}{ Postoxygenator samples } \\
\hline $\mathrm{pH}$ & $7.49 \pm 0.09$ & $7.485 \pm 0.12$ & .897 \\
\hline $\mathrm{PCO}_{2}(\mathrm{~mm} \mathrm{Hg})$ & $30.2 \pm 8.45$ & $31.7 \pm 9.2$ & .645 \\
\hline $\mathrm{Po}_{2}(\mathrm{~mm} \mathrm{Hg})$ & $478 \pm 87.8$ & $453 \pm 91.4$ & .452 \\
\hline $\operatorname{Hgb}(\mathrm{g} / \mathrm{dL})$ & $12.1 \pm 2.8$ & $12.4 \pm 3.2$ & .876 \\
\hline
\end{tabular}

TABLE 2. Continued

\begin{tabular}{cccc}
\hline Parameters & Group NS & Group C & $\begin{array}{c}\boldsymbol{P} \\
\text { value }\end{array}$ \\
\hline $\mathrm{SO}_{2}(\%)$ & 100 & 100 & 1 \\
$\mathrm{BRF}(\%)$ & & & \\
$\left(\mathrm{PrexyO}_{2}-\mathrm{ScvO}_{2}\right) /$ & $5.31 \pm 3.68$ & $29.43 \pm 8.96$ & $<. \mathbf{0 0 0 1}$ \\
$\left(\mathrm{PostOxyO}_{2}\right.$ & & & \\
$\left.-\mathrm{ScvO}_{2}\right) \cdot 100$ & & & \\
\hline
\end{tabular}

Values are mean \pm standard deviation. $P<.05$ is significantly different. $B R F$, Blood recirculation fraction; $V V-E C M O$, venovenous extracorporeal membrane oxygenation; $\mathrm{CO}$, cardiac output; $\mathrm{SO}_{2}$, oxygen saturation; $\mathrm{FIO}_{2}$, fraction of inspired oxygen; $M V$, respiratory minute volume; $T V$, tidal volume; $P E E P$, positive end-expiratory pressure; $P I P$, peak inspiratory pressure; $C O$, cardiac output; $B S A$, body surface area; $C I$, cardiac index; $\mathrm{PaCO}_{2}$, arterial carbon dioxide tension; $\mathrm{PO}_{2}$, oxygen tension; $\mathrm{Hg}$, hemoglobin concentration; $\mathrm{SO}_{2}$, oxygen saturation; $\mathrm{PO}_{2}$, carbon dioxide tension; $\mathrm{ScVO}_{2}$, central venous oxygen saturation.

$[P=.0315]$, respectively) in which pulmonary function is necessary (with an increase in blood oxygen content significant from $16.09 \pm 1.45$ to $17.38 \pm 1.82[P=.048]$ after pulmonary transit) to obtain a radial artery oxygen content similar to group NS $(17.59 \pm 1.76$ vs $17.38 \pm 1.82$ $[P=.762]$, respectively). Moreover, in group NS, at the same elevated flow levels, BRF was significantly lower and more uniform than that of group $\mathrm{C}(5.3 \pm 3.6$ vs $29.43 \pm 8.9[P<.0001]$, respectively). Regarding carbon dioxide removal, both cannula configurations are similar in efficacy and efficiency.

\section{DISCUSSION}

Advances in mechanical ventilation and new ventilation strategies designed to promote optimal ventilation and perfusion while sparing lung parenchyma from barotraumas have been applied for more than 10 years, as SARF mortality remains as high as $66 \%{ }^{2,6}$ High mortality is caused by many complications, such as multiple-organ failure, sepsis, stroke, myocardial infarction, and progressive lung injury. All occur from the underlying disease or from prolonged positivepressure mechanical ventilation and high-concentration oxygen toxicity with consequent irreversible parenchyma injury. Parenchymal injury is the principal means of failure in these patients. ${ }^{1-4,6}$ SARF patients may benefit from VV-ECMO support and from "pulmonary rest" setting by reduction of ventilatory pressure, oxygen concentration, and as a consequence significant reduction of VILI and improvement of pulmonary recovery. Careful selection of patients who have had unsuccessful conventional ventilator therapy and the application of ECMO earlier in the disease process have likely affected outcome: it is important to limit lung injury both before and during ECMO support to maximize the chance of recovery. ${ }^{16,17}$ Notwithstanding the documented success of non-adult ECMO for SARF (survival is $71 \%-88 \%$ ), significant controversy remains over the application of ECMO. ${ }^{3,5,8-10,14,18,19}$ Different experimental ${ }^{20-23}$ and clinical ${ }^{4,24}$ reports show that VILI 
also causes renal, cardiac, liver failure, and other systemic consequences, probably owing to inflammatory mediators delivered from the damaged lung when high-pressure mechanical ventilation is continued. ${ }^{21}$ During ECMO, obtaining an optimal blood oxygenation level is possible only if the VV-ECMO technique permits it: our new cannula setting, the $\chi$-configuration, reduces recirculation and permits a very high ECMO flow related to the patient's CO, avoiding invasive surgical methods, which are to date the only methods that permit similar results. ${ }^{18,25}$ Although percutaneous VA-ECMO permits a higher and more consistent oxygen delivery, VV-ECMO reduces invasiveness and major complications related to arterial cannulation, impaired cardiac performance, decreased coronary and cerebral oxygen transport and autoregulation, altered regional blood flow to vital organ, increased pulmonary resistance, and more. , $^{3,10,16}$

Sufficient blood oxygenation with VV-ECMO is more difficult to achieve in the adult population than in the pediatric population. Many problems arise, such as recirculation, high patient $\mathrm{CO}$, limited use of double-lumen cannulas, and their flow limits. ${ }^{13,18,19}$ In high-flow VV-ECMO, recirculation plays a central role in limiting oxygen delivery to the patient. Different factors influence recirculation (eg, cardiac function, tricuspid valve regurgitation, and VV-ECMO flow); however, the relative positions of outflow and inflow cannulas are its major determinants. No complications related to cannula positioning were registered during our experience.

From August 2007 to October 2010, we have prospectively enrolled 30 consecutive patients. In all reported patients the risk of mortality was $80 \%$ to $100 \%$ if conventional treatment was continued. ${ }^{19-21}$ Total survival was equal to $73.3 \%$, comparable with other published studies. ${ }^{8-11,16,19}$ In group NS the survival was $87.5 \%$, and if there is no statistically significant difference from group C survival $(57.14 \% ; P=.058)$ the better outcome could be related to better patient systemic oxygenation, reduced $\mathrm{BRF}$, and the consequent possibility of a very protective ventilatory strategy and a real pulmonary rest. Our data seem to confirm that $\chi$-configuration is capable of inducing a more prompt and more complete pulmonary recovery (with a reduction of on-ECMO time and ECMO-related complications) and consequently reduces the incidence of pulmonary fibrosis. Moreover, our data demonstrate that at equal ECMO flow ( $80 \%$ of the patient's CO), our new $\chi$-configuration strategy permitted reduction in recirculation fraction, a higher systemic arterial oxygen tension, and a lower ECMO flow to obtain sufficient patient oxygenation (reducing the side effects of extracorporeal circulation, such as hemolysis, thrombocytopenia, and inflammation).

\section{CONCLUSIONS}

Treating patients who have SARF with VV-ECMO has become an important tool in advanced critical care medi- cine. Nevertheless, it is at times ineffective, especially in the presence of a high BRF.

We have introduced a novel but simple strategy for optimizing VV-ECMO oxygenation, the $\chi$-configuration, consisting of a particular arrangement of the intra-atrial cannula position and an original self-made inflow cannula modification. This new strategy allowed higher separation between inflow and outflow blood flows, thus significantly reducing recirculation and greatly increasing systemic oxygen saturation and delivery. Venoarterial ECMO and other invasive and hazardous surgical procedures were avoided. No major complications related to the modified inflow cannula were observed, including arrhythmias.

In our opinion, the $\chi$-configuration allows very protective ventilator settings when trying to achieve lung rest, avoiding overall VILI, and consequently improves patient outcomes and seems to reduce ECMO time, time to pulmonary recovery, intensive care unit stay, and hospital costs.

\section{References}

1. Bernard GR, Artigas A, Brigham KL, Carlet J, Falke K, Hudson L, et al. Consensus Committee. Report of the American-European Consensus conference on acute respiratory distress syndrome: definitions, mechanisms, relevant outcomes, and clinical trial coordination. J Crit Care. 1994;9:72-81

2. Rubenfeld GD, Caldwell E, Peabody E, Weaver J, Martin DP, Neff M, et al. Incidence and outcomes of acute lung injury. N Engl J Med. 2005;353: 1685-93.

3. Hemmila MR, Napolitano LM. Severe respiratory failure: advanced treatment options. Crit Care Med. 2006;34(suppl):S278-90.

4. Amato MB, Barbas CS, Medeiros DM, Magaldi RB, Schettino GP, LorenziFilho G, et al. Effect of a protective-ventilation strategy on mortality in the acute respiratory distress syndrome. $N$ Engl J Med. 1998;338:347-54.

5. Ullrich R, Lorber C, Röder G, Urak G, Faryniak B, Sladen RN, et al. Controlled airway pressure therapy, nitric oxide inhalation, prone position, and extracorporeal membrane oxygenation (ECMO) as components of an integrated approach to ARDS. Anesthesiology. 1999;91:1577-86.

6. Rubenfeld GD, Herridge MS. Epidemiology and outcomes of acute lung injury. Chest. 2007;131:554-62.

7. Hill JD, O’Brien TG, Murray JJ, Dontigny L, Bramson ML, Osborn JJ, et al. Prolonged extracorporeal oxygenation for acute post-traumatic respiratory failure (shock-lung syndrome). Use of the Bramson membrane lung. N Engl J Med. 1972;286:629-34.

8. Mols G, Loop T, Geiger K, Farthmann E, Benzing A. Extracorporeal membrane oxygenation: a ten-year experience. Am J Surg. 2000;180:144-54.

9. Masiakos PT, Islam S, Doody DP, Schnitzer JJ, Ryan DP. Extracorporeal membrane oxygenation for nonneonatal acute respiratory failure. Arch Surg. 1999 134:375-80.

10. Peek GJ, Moore HM, Moore N, Sosnowski AW, Firmin RK. Extracorporeal membrane oxygenation for adult respiratory failure. Chest. 1997;112: 759-64

11. Peek GJ, Mugford M, Tiruvoipati R, Wilson A, Allen E, Thalanany MM, et al CESAR trial collaboration. Efficacy and economic assessment of conventional ventilatory support versus extracorporeal membrane oxygenation for severe adult respiratory failure (CESAR): a multicentre randomised controlled trial. Lancet 2009;374:1351-63.

12. Ichiba S, Peek GJ, Sosnowski AW, Brennan KJ, Firmin RK. Modifying a venovenous extracorporeal membrane oxygenation circuit to reduce recirculation. Ann Thorac Surg. 2000;69:298-9.

13. Rais-Bahrami K, Walton DM, Sell JE, Rivera O, Mikesell GT, Short BL. Improved oxygenation with reduced recirculation during venovenous ECMO: comparison of two catheters. Perfusion. 2002;17:415-9.

14. Peris A, Cianchi G, Biondi S, Bonizzoli M, Pasquini A, Bonacchi M, et al. Extracorporeal life support for management of refractory cardiac or respiratory failure: initial experience in a tertiary centre. Scand J Trauma Resusc Emerg Med. 2010;18:28. Published online 2010 May 21. 
15. Rich PB, Awad SS, Crotti S, Hirschl RB, Bartlett RH, Schreiner RJ. A prospective comparison of atrio-femoral and femoro-atrial flow in adult venovenous extracorporeal life support. J Thorac Cardiovasc Surg. 1998;116: 628-32.

16. Nehra D, Goldstein AM, Doody DP, Ryan DP, Chang Y, Masiakos PT. Extracorporeal membrane oxygenation for nonneonatal acute respiratory failure: the Massachusetts General Hospital experience from 1990 to 2008. Arch Surg. 2009; 144: 427-32.

17. Pranikoff T, Hirschl RB, Steimle CN, Anderson HL 3rd, Bartlett RH. Mortality is directly related to the duration of mechanical ventilation before the initiation of extracorporeal life support for severe respiratory failure. Crit Care Med. 1997;25: 28-32.

18. Chiu KM, Li SJ, Hung FM, Chu SH. Tzu-Yulin. Right heart bypass for acute traumatic respiratory distress syndrome. ASAIO J. 2005;51:826-8.

19. Hemmila MR, Rowe SA, Boules TN, Miskulin J, McGillicuddy JW, Schuerer DJ, et al. Extracorporeal life support for severe acute respiratory distress syndrome in adults. Ann Surg. 2004;240:595-605; discussion 605-597.
20. Ferguson ND, Frutos-Vivar F, Esteban A, Gordo F, Honrubia T, Peñuelas O, et al. Clinical risk conditions for acute lung injury in the intensive care unit and hospital ward: a prospective observational study. Crit Care. 2007;11: R96.

21. Erickson SE, Martin GS, Davis JL, Matthay MA, Eisner MD. NIH NHLBI ARDS Network. Recent trends in acute lung injury mortality: 1996-2005. Crit Care Med. 2009;37:1574-9.

22. Kolobow T, Moretti MP, Fumagalli R. Severe impairment of lung function induced by high peak airway pressure during mechanical ventilation: an experimental study. Am Rev Respir Dis. 1987;135:312-5.

23. Parker JC, Hernandez LA, Peevy KJ. Mechanisms of ventilator induced lung injury. Crit Care Med. 1993;21:131-43.

24. The Acute Respiratory Distress Syndrome Network. Ventilation with lower tidal volumes as compared with traditional tidal volumes for acute lung injury and the acute respiratory distress syndrome. $N$ Engl J Med. 2000;342:1301-8.

25. Maclaren G, Cove M, Kofidis T. Central extracorporeal membrane oxygenation for septic shock in an adult with H1N1 influenza. Ann Thorac Surg. 2010;90:e34-5. 